\title{
Recommendations regarding Organizations and Institutions of the Business World
}

The following section reproduces policy recommendations for governments, political organizations, as well as for institutions and organizations of the business world how to fight antisemitism. These were developed for the Catalogue of Policies to Combat Antisemitism ${ }^{1}$ and grew out of all research presented at the conference “An End to Antisemitism!" in Vienna, February 18-22, 2018. These studies pertain to the emergence and growth of antisemitism within the worlds of business, jurisprudence, policy and practical politics. They concern the effects of antisemitism within the mentioned areas and help to develop recommendations for the fight against it.

The contributions in questions can be found in the previous section of this volume. Further articles that contributed to the recommendations presented below are published in volume 5 of the conference proceedings An End to Antisemitism!, forthcoming.

Many companies engage in businesses that have nothing to do with antisemitism and antisemitic agitation, while others either accidentally or intentionally get involved with antisemitism. Examples of the latter include music labels, publishing houses, online bookdealers, online book repositories, social media platforms, etc. All companies and businesses, though, are bound to avoid any form of discrimination against their workforce or in their business dealings. The recommendations of this chapter thus concern mainly antisemitic discrimination and business practices that support antisemitism. The question of anti-Zionist boycotts of the State of Israel will be dealt with in detail below because, for the most part, the antisemitism inside the BDS movement can best be addressed by political and not by economic decision makers.

There are various levels of decision makers and influencers in the business world and many of them could potentially have a significant impact on the fight against antisemitism. The recommendations of this catalogue, therefore, are addressed not only to top level managers and business owners but to all levels of management. Some recommendations regard not only businesses in the narrower sense but also decision makers responsible for the workforce of administrations and other institutions.

1 A. Lange, A. Muzicant, D. Porat, L. H. Schiffman, M. Weitzman, An End to Antisemitism! A Catalogue of Policies to Combat Antisemitism (Brussels: European Jewish Congress, 2018), 93134.

Ә OpenAccess. ( ) 2019, Armin Lange, Kerstin Mayerhofer, Dina Porat, Lawrence H. Schiffman, published by De Gruyter. (cc) BY-NC-ND This work is licensed under the Creative Commons Attribution-NonCommercialNoDerivatives 4.0 License https://doi.org/10.1515/9783110618594-039 
Some principal reflections about antisemitism and the business world are appropriate before making concrete recommendations on how decision makers and influencers of the business world could help to combat antisemitism. The subject of antisemitism and its relation to business has a very long history. In the Middle Ages, in both Christianity and Islam, numerous restrictions were placed on Jews in terms of their business activity, forcing them increasingly, especially in the Christian world, into the position of moneylenders and financiers. In the Muslim world, Jews found it easier to enter into a wider variety of occupations in pre-modern times, but nonetheless still found themselves at an economic disadvantage and unable to enter many professions. With the Enlightenment and the Emancipation, Jews entered into what they thought would be a free world in terms of occupations and professions. Unfortunately, they soon found themselves restricted by a variety of quotas that affected entry into universities, professional training programs, and the securing of employment.

In the last century, despite antisemitic restrictions in virtually all their places of settlement, Jews distinguished themselves in medicine, law and business and, as higher education became de rigueur, they constituted virtually everywhere a larger percentage of the student body than their numbers would have indicated. At the same time, the number of Jews denied entry to professions, not hired because they were Jewish, not allowed into professional clubs and organizations, and otherwise hindered in what we would regard today as normal human rights was very large. Not so long ago, such second-class status was regularly visited on Jewish students and professionals in the Soviet Union and in East European countries in general. More importantly, such behavior still continues in the business world, and concrete steps must be taken to eliminate this form of antisemitic behavior whenever it is encountered.

We should also note the unwillingness of some Arab countries to do business with Jewish owned and/or Jewish identified companies and, more importantly, even to allow those who admit to being Jewish to enter their countries. This clearly affects opportunities of employment and business for individual Jews and Jewish companies. This attitude stems both from the classic secondclass status of Jews in the Islamic world, based on the teachings of Islam, and at the same time from the modern political situation in terms of the Arab-Israeli conflict.

An important area of antisemitism as it relates to business is that the prominent role of Jews in the professions and in international business has contributed to the creation of a conspiratorial mythology that has a long history as well. Today, people often hear comments that allege that Jews "have too much influence," do not like physical work, keep others out of business, or use shady business practices. Society must vigorously combat statements of mendacious, dehumanizing, de- 
monizing, or stereotypical allegations about Jews, and reject portrayal of the power of Jews as a collective, such as-especially but not exclusively-the myth about a world Jewish conspiracy or of Jews controlling the media, economy, government, or other societal institutions. Such a depiction is simply an antisemitic canard and propaganda ploy, often graphically portrayed.

These principal reflections show, that beyond a general participation in the fight against antisemitism, decision makers in the business world can contribute in several respects to combating antisemitism:

- Reversing discrimination in the workforce

- Reversing discrimination of Jewish and/or Israeli companies and, rather, seeking business with Israel

- Ending the marketing of antisemitic content

- Condemning antisemitism and arguing against conspiracy theories.

To fight antisemitism successfully in these areas, we advise the same five-step process that we recommended to all other decision makers:

1. Assessment: Assessing the level of antisemitism in a business, a company, a business- related organization, or a profession.

2. Comprehending the problem: Analyzing what motivates antisemitism and/or antisemitic discrimination in a business, a company, a business-related organization, or a profession.

3. Awareness-raising: All members of a business, a company, a business-related organization, or a profession need to be sensitized towards the antisemitism in their organization.

4. Application of policies for combating antisemitism.

5. Adjusting the general policies to combat antisemitism: The general policies suggested below need to be adjusted to the specific needs of each business, company, business- related organization, or profession.

\section{Assessment: Assessing the Level of Antisemitism in a Business, a Company, a Business-related Organization, or a Profession}

Decision makers in the business world have to realize that they have an obligation to assess the manifestations of antisemitism in their enterprises guided by the IHRA's Working Definition of Antisemitism. Assessment of the level of antisemitism should be undertaken in cooperation with Jewish organizations and by independent scholarly/scientific institutions. 
Antisemitism may be present in hiring practices, promotions, assignments, and other job-related tasks. It may be also present in a general culture of toleration for antisemitic remarks or jokes, and in business practices that do not allow Jewish employees to fully practice Jewish observances. If a business leader determines that in his/her enterprise antisemitism is at a level that can be dealt with by reform according to the recommendations made below, he/she is strongly advised to institute reforms that will eliminate it. After such a program, the level of antisemitism should be assessed again to see how effective the measures were.

\section{Comprehending the Problem: Analyzing what Motivates Antisemitism and/or Antisemitic Discrimination in a Business, a Company, a Business-related Organization, or a Profession}

In each business, company, business-related organization, or profession, antisemitic discrimination and antisemitic acts and convictions can have different causes. Therefore, for each of these entities, it needs to be asked individually what motivates antisemitism and what encourages the antisemitic attitudes of those who participate in it. Is the antisemitism accidental or intentional? Is it influenced by Christian, Muslim, Anti-Zionist or other antisemitic prejudices? Is it economically driven or not? How does it express itself?

\section{Awareness-raising: All Members of a Business, a Company, a Business-related Organization, or a Profession Need to Be Sensitized towards the Antisemitism in their Organization}

To raise the awareness of antisemitism with decision makers and influencers in a business, a company, a business-related organization, or a profession, we recommend that they participate in special training courses and seminars about both the history and culture of antisemitism as well as about the history, culture, and religious customs of Judaism. These training courses should enable decision makers and influencers to recognize all forms of antisemitism, including accidental and structural antisemitism, but also to develop more appreciation for the cultural and religious needs of their Jewish employees and business partners. A fur- 
ther topic of such training courses and seminars should be all forms of discrimination in the workplace and how discrimination can be fought effectively.

\section{Application of Policies for Combating Antisemitism}

The two main areas to which the following policy recommendations apply are antisemitic discrimination and the marketing of antisemitic content. Nevertheless, due to their influence, decision makers and influencers in the business world can make a difference in the fight against antisemitism in many other areas as well. One of the most important general recommendations that applies to all interactions with antisemitism in the business world is

to adopt the Working Definition of Antisemitism in the workplace and business dealings, i.e., to hold people accountable for their policies or comments that are intended to harm Jews as a group or target one person.

\subsection{Reversing Discrimination in Workspaces and against Jewish and Israeli Businesses}

In the business world, antisemitic discrimination includes discrimination against Jewish employees in workplaces and economic discrimination against Jewish companies and the State of Israel by boycotting them.

With regard to antisemitic discrimination in workplaces, it needs to be remembered that United Nations human rights expert and Special Rapporteur to the UN General Assembly on freedom of religion or belief, Heiner Bielefeldt, stated in his 2014 report $^{2}$ that freedom to manifest one's religion or belief without discrimination should also be protected in the area of employment. He urged all governments to take every appropriate measure to prevent and eliminate all forms of intolerance and discrimination based on religion or belief. Focusing on eliminating religious intolerance and discrimination in the workplace, Bielefeldt specifically addressed issues affecting religious Jews, such as religious garb, dietary restrictions, and

2 United Nations General Assembly, Interim Report of the Special Rapporteur on Freedom of Religion or Belief, issued August 5, 2014, https://www.ohchr.org/Documents/Issues/Religion/A.69. 261.pdf. 
working on Shabbat and holidays. Likewise, failure of employers to respect Jewish traditions and practices at work creates an unwelcoming environment. Jews who choose to express their identity might have to forgo professional opportunities. Some employers prevent or restrict the open display of religious identities at work. In other situations, only the followers of mainstream religions or beliefs are granted an opportunity to manifest their convictions openly at the workplace, while individuals belonging to minority communities, sceptics, atheists or dissenters are forced to conceal their positions in order to avoid harassment by colleagues, customers or employers. The Special Rapporteur reported about incidents of pressure exercised by colleagues or employers on members of religious minorities to remove their religious garments, to consume religiously prohibited food, or to eat during religious fasting periods. Moreover, women may suffer from multiple and/or intersectional forms of discrimination or related abuses in the workplace, often originating from both their gender and their religious or belief background.

Bielefeldt recommends encouraging employers to use reasonable accommodation as a managerial tool outside the realm of law. In the long run, measures of accommodation can even have positive economic effects by enhancing the reputation of an institution or company, by reinforcing a sense of loyalty and identification within the staff, and by facilitating a creative atmosphere in which diversity is appreciated as a positive asset.

Many governments have laws rejecting discrimination for race, religion, nationality, sexual orientation, gender, age, etc. in hiring and promotion. These laws apply to Jews as much as to any other group in the corporate world.

Based on Bielefeldt, the following policies to fight antisemitic discrimination in the workforce are therefore recommended:

- Reject discrimination against Jews or Israelis in the corporate world.

- Employers, trade unions and consumer organizations have a responsibility to combat all forms of intolerance and discrimination in the workplace, including antisemitism.

- In larger companies, an antidiscrimination officer who controls how people are hired should be installed.

- Antisemitic managers or employees should be informed that their actions are not in consonance with company policy and, if antisemitic actions continue, such managers and employees should not be retained.

- Maintain a culture of open and trustful communication between employers, managers and staff, always including religious or belief minorities, who should feel encouraged to voice their specific concerns and needs.

- Governments must set positive examples of respect for religious diversity in their own employment policies within state institutions. 
- Businesses should establish an appropriate infrastructure of training and advisory services based on human rights with the aid of national human rights institutions.

- Continuing education for employees should include the history and culture of Judaism and Jews as well as the history of antisemitism.

- Afford equal opportunity for all employees in hiring and promotions.

- Support the creation of a hotline with the office of an envoy for combating antisemitism to report antisemitic incidents and to seek help against antisemitic discrimination. Inform all members of the workforce and staff about its existence once it is created.

\subsection{Reversing Economic Discrimination against Jews and the State of Israel, including BDS}

Economic discrimination against Jews has a long history, as detailed at the beginning of this chapter.

Decision makers and influencers in the business world should do their utmost to reject and actively oppose economic discrimination perpetrated against any Jewish entity.

A more complicated form of economic discrimination in the world of business today is connected with what began as the Arab boycott and what is now known as BDS, Boycott, Divestment and Sanctions. We will engage with this topic in more detail below. Here it suffices to say that making the boycott even more insidious, companies seeking to do business in the Arab world were sworn away from doing business with Jewish-identified companies, especially those with Israeli contacts. This tertiary boycott affected businesses owned by Jews throughout the world, but also suffered setbacks when legally confronted.

To fight all economic discrimination against Jewish entities we recommend the following policies to decision makers in the business world:

- Promote the initiative to make BDS and other such boycotts illegal.

- Publically challenge organizations that refuse to do business with Israel or that will not deal with companies that trade with or have offices in Israel.

- Do not subscribe to boycotting Israeli imports. Do not refuse to buy products that are sold in Israel, preferring rather to buy from companies that do not do business with Israel.

- Do not allow companies to remove their investments in the Israeli economy.

- Do not subscribe to sanctions against Israel. 
- Encourage Muslim-Jewish business enterprises as a way to break down stereotypes and antagonisms.

- Make sure to treat Jewish companies worldwide and Israeli companies in particular the same as any other company in your business dealings.

- Make use of Israeli inventions and invest in Israeli companies where applicable.

\subsection{Ending the Marketing of Antisemitism}

Companies have a responsibility for what they market. Antisemitic agitation led to the most horrendous crimes in history. Whoever markets antisemitic agitation contributes to its success and is thus responsible for the crimes it wants to provoke. Amazon as the largest Internet retailer is an example of this problem, as detailed in the part on recommendations for cultural decision makers. For instance, a book by Joseph Goebbels and the Nazi cartoonist Mjölnir entitled Isidor that is a collection of typical Nazi antisemitic agitation ${ }^{3}$ is available at Amazon. Companies have a responsibility to refrain from marketing any antisemitic agitation. This particularly applies to contents that are known to have incited genocide in the past.

We would like to guide business decision makers for this purpose with the following policy recommendations:

- Do not market or sell any content that is included in the recommended blacklists.

- Do not market any goods and services that are antisemitic or that may indirectly encourage antisemitism.

- Advocate legislation that makes it illegal for companies to market antisemitic memorabilia and content.

- Create and/or market positive contents about Jews and accurate descriptions of the history of antisemitism to counter the effects of antisemitic agitation. (For more details, see the recommendations addressed to religious, cultural, and Internet decision makers.)

- Encourage your business partners follow the same policies.

3 Cf. https://www.amazon.de/Goebbels-Mjoelnir-Isidor-Zeitbild-Hardcover/dp/9333178767 (accessed October 4, 2018). 


\subsection{Condemning Antisemitism and Arguing against Conspiracy Theories}

Businesses have a unique ability to condemn discrimination and hate and should use that ability to condemn antisemitism publicly. For this purpose we recommend the policies below:

- Refrain from giving legitimacy to antisemites by refusing to participate in or speak at their events. Deny them any platform related to your company.

- Support the sanction of Iran and countries that incite to antisemitism. The Iranian regime remains a central and belligerent player in promoting support for global terrorism, antisemitism and Holocaust denial.

- Refuse to cooperate with other antisemitic entities, whether regimes or business enterprises.

- Ally with law enforcement to identify and prosecute bias crimes.

- Decry disinformation, hate speech, antisemitic rumors, and antisemitic propaganda such as the Protocols of the Elders of Zion.

- Argue forcefully and publicly against economic and fiscal antisemitic world conspiracy theories, including statements such as "Jews have too much power in the business world or in international financial markets." ${ }^{4}$

\section{To Summarize}

Decision makers and influencers in the business world should do everything they can to avoid and/or reverse antisemitic discrimination in the workplace and economic discrimination against Jewish entities. They should avoid the marketing of antisemitic contents and memorabilia because such contents provoke hate crimes. It is well known that in the past, such provocations ultimately contributed to genocide. Business decision makers should use their authority to argue publicly against antisemitic slanders regarding Jewish fiscal and other world conspiracies. Rather than acquiesce in boycotts and sanctions, they should use their influence to further the fight against antisemitism in the business and political worlds.

4 Anti-Defamation League, "ADL Global 100: An Index of Anti-Semitism: 2015 Update in 19 Countries,” https://global100.adl.org/public/ADL-Global-100-Executive-Summary2015.pdf, 6. 
